\title{
Erratum to: Olfactory responses of Neoseiulus cucumeris (Acari: Phytoseiidae) to odors of host plants and Frankliniella occidentalis (Thysanoptera: Thripidae)-plant complexes
}

\author{
Feng Zhong • Yu-Rong He • Yan Gao • \\ Guo-Jun Qi • Chen-Yin Zhao • Li-Hua Lu
}

Published online: 14 September 2011

(C) Springer Science+Business Media B.V. 2011

\section{Erratum to: Arthropod-Plant Interactions \\ DOI 10.1007/s11829-011-9135-6}

In the paper entitled "Olfactory responses of Neoseiulus cucumeris (Acari: Phytoseiidae) to odors of host plants and Frankliniella occidentalis (Thysanoptera: Thripidae)-plant complexes" (Arthropod-Plant Interactions, Online First ${ }^{\mathrm{TM}}$, April 29, 2011), an incorrect sample size was inadvertently used and consequently some of statistical analysis between odors were not significantly different based on individual amount instead of percentage. The experimental replicates were added to 56-96 individual thrips and then all test figures were re-analyzed. The raw data and statistical analysis were computed again.

Under the heading "Y-tube olfactometer tests," paragraph 2, line 7, the sentence should read as follows:

"For each treatment, 56-94 individuals were examined."

Under the heading "Data analysis," line 1, the sentence should read as follows:

"The Pearson chi-square test was performed on the individual amount of predators attracted toward the odor sources."

The online version of the original article can be found under doi:10.1007/s11829-011-9135-6.

F. Zhong · Y.-R. He · C.-Y. Zhao

College of Natural Resources and Environment, South China

Agricultural University, 510642 Guangzhou, Guangdong, China

F. Zhong · Y. Gao · G.-J. Qi · L.-H. Lu ( $ه)$

Plant Protection Research Institute, Guangdong Academy of Agricultural Sciences, 510640 Guangzhou, Guangdong, China

e-mail: lhlu@gdppri.com
Please find the correct statistical data of "Results," under the heading "Results" that should be regarded by the reader as the final version.

\section{Experiment 1}

Compared with clean air (CA), N. cucumeris showed a preference to the odors of undamaged eggplant $\left(\chi^{2}=\right.$ 14.34, $P<0.05)$. The same results were observed with the odors of undamaged pepper $\left(\chi^{2}=17.00, P<0.05\right)$ and undamaged tomato $\left(\chi^{2}=8.32, P<0.05\right)$ (Fig. 1).

\section{Experiment 2}

$N$. cucumeris adults responded more significantly to the infested eggplant than to undamaged, mechanically damaged, or pre-infested eggplant $\left(\chi^{2}=4.07, \chi^{2}=5.08\right.$, $\chi^{2}=6.78, P<0.05$, Fig. 2). Similarly, the adults preferred the odors of infested pepper to undamaged, mechanically damaged, and pre-infested pepper $\left(\chi^{2}=\right.$ 8.00, $\chi^{2}=4.26, \chi^{2}=5.23, P<0.05$, Fig. 2). The same results were observed with the tomato.

\section{Experiment 3}

We analyzed the olfactory responses of $N$. cucumeris to different host plants with different treatments. $N$. cucumeris adults preferred the odors of undamaged eggplant to undamaged pepper $\left(\chi^{2}=16.78, P<0.05\right.$, Fig. 3$)$. 
Fig. 1 Olfactory responses of Neoseiulus cucumeris to undamaged plants versus clean air in a Y-tube olfactometer

Fig. 2 Olfactory responses of Neoseiulus cucumeris to

infested plants versus the plants of other different treatments in a Y-tube olfactometer

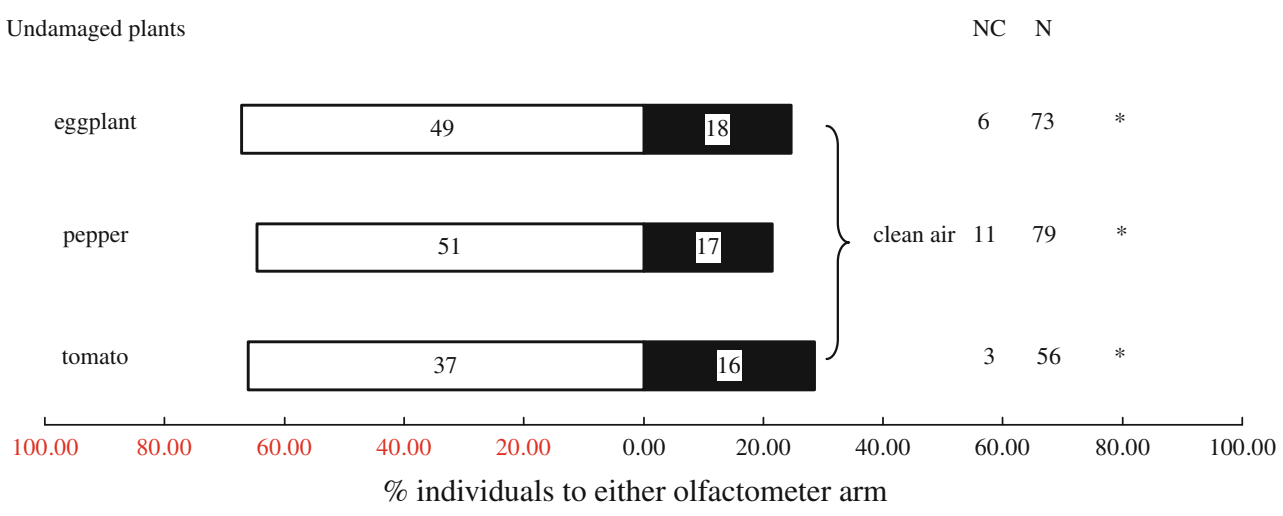

Eggplant

Eggplant

NC N

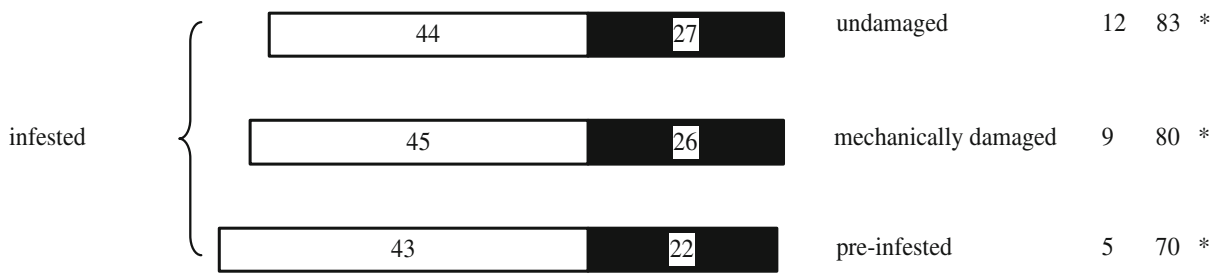

Pepper

Pepper

NC N
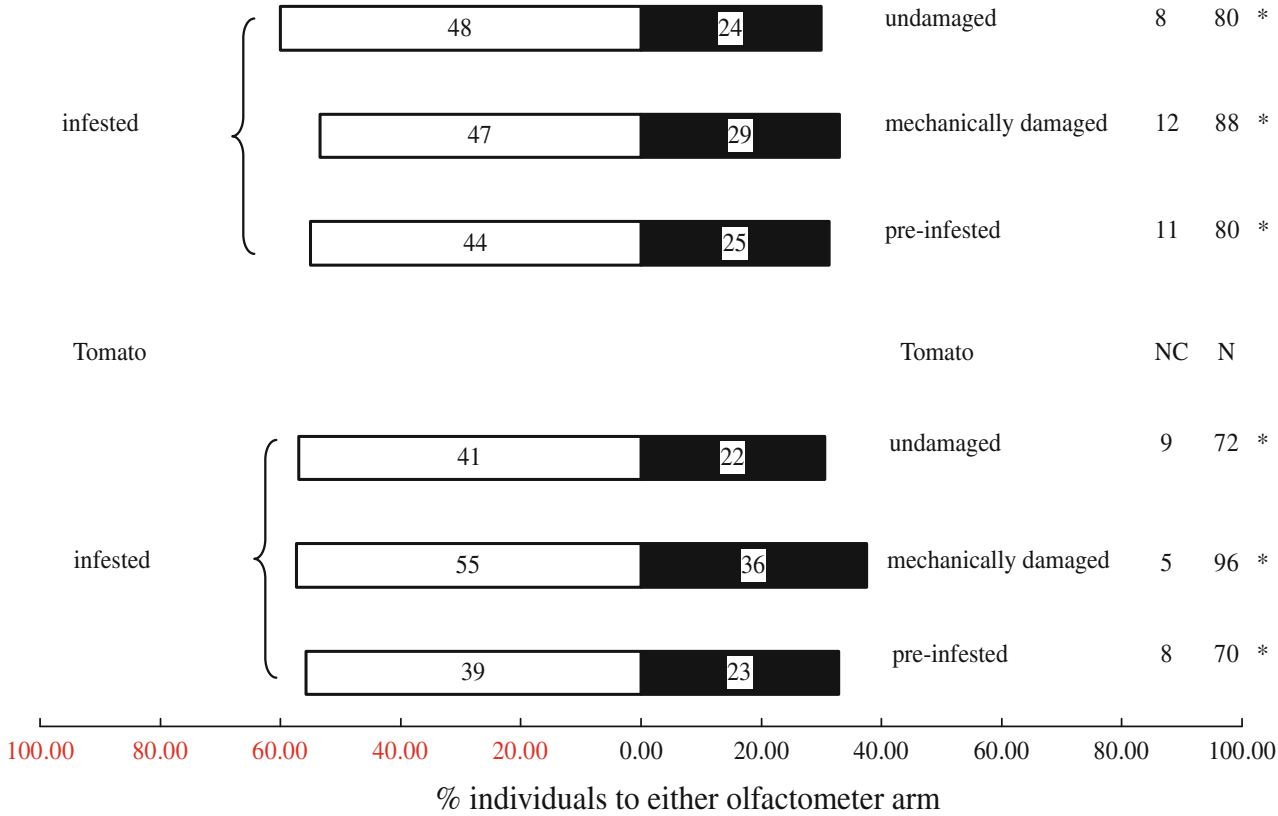

Similarly, the adults preferred the odors of undamaged tomato to pepper $\left(\chi^{2}=8.67, P<0.05\right.$, Fig. 3$)$. And compared with odors of undamaged tomato, $N$. cucumeris did not significantly respond to odors of undamaged eggplant $\left(\chi^{2}=0.02, P>0.05\right.$, Fig. 3$)$. The same results were

observed with the odors of the mechanically damaged eggplant, pepper, and tomato, and pre-infested eggplant, pepper, and tomato (Fig. 3). Compared with odors of infested tomato, $N$. cucumeris adults significantly responded to odors of infested eggplant $\left(\chi^{2}=4.00, P<0.05\right.$, 
Fig. 3 Olfactory responses of Neoseiulus cucumeris to different plants with different treatments in a Y-tube olfactometer

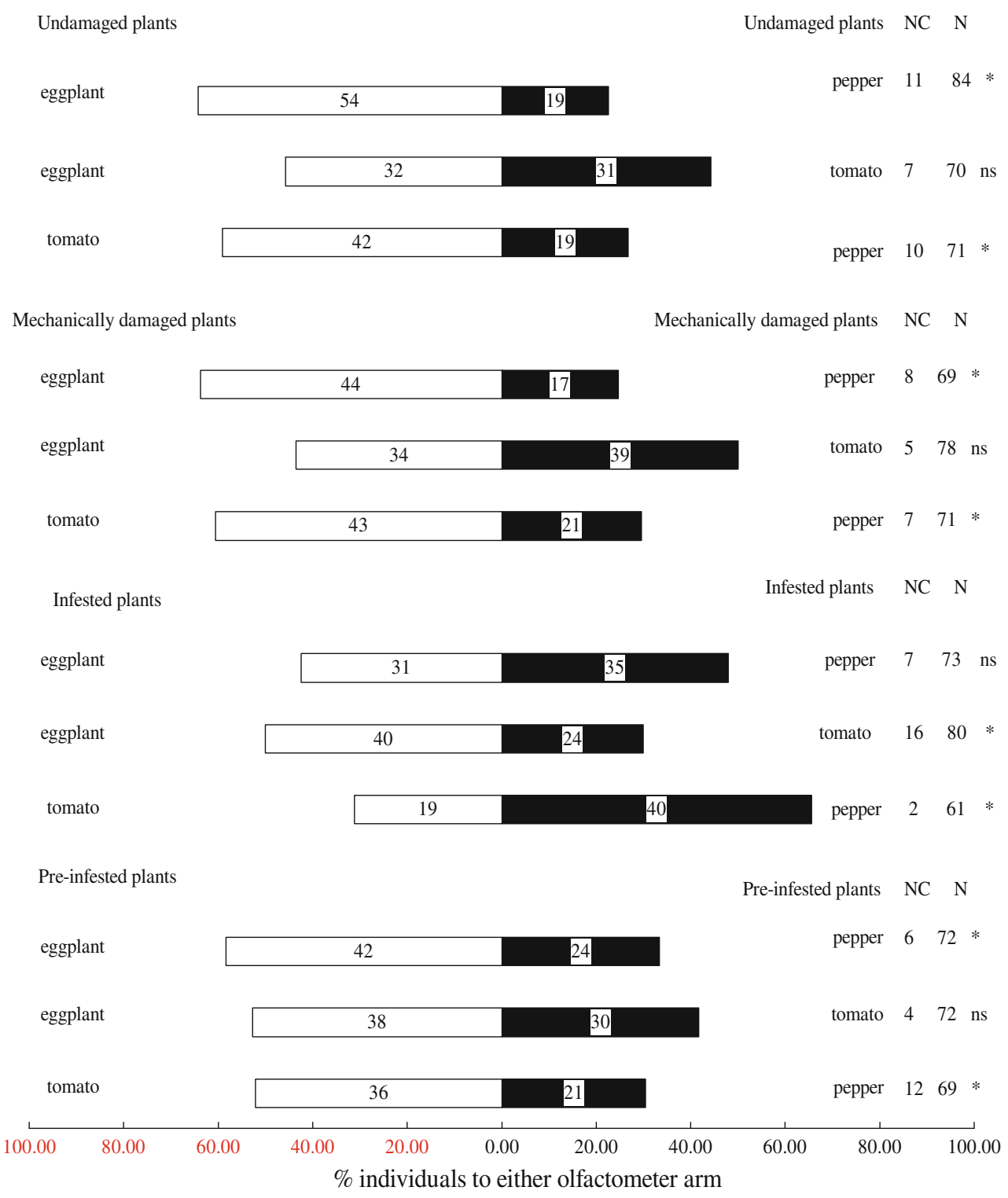

Fig. 3). The adults preferred the odors of infested pepper to infested tomato $\left(\chi^{2}=7.47, P<0.05\right.$, Fig. 3$)$. There was no significant difference of $N$. cucumeris in making a choice between infested eggplant and infested pepper $\left(\chi^{2}=0.24, P>0.05\right.$, Fig. 3$)$.

We regret any confusion this error has caused. 